\title{
In vitro follicular development of cryopreserved mouse ovarian tissue
}

\author{
Miwa Segino ${ }^{1,2}$, Mario Ikeda ${ }^{1}$, Fumiki Hirahara ${ }^{1}$ and Kahei Sato ${ }^{2}$ \\ ${ }^{1}$ Department of Obstetrics and Gynecology, Yokohama City University Medical School, 4-57 Urafune-Cho, \\ Minami-Ku, Yokohama, Japan and ${ }^{2}$ Department of Applied Biological Science, Nihon University, 1866 Kameino, \\ Fujisawa, Japan \\ Correspondence should be addressed to M Segino, Department of Obstetrics and Gynecology, Yokohama City University \\ Medical School, 4-57 Urafune-Cho, Minami-Ku, Yokohama, 232-0024 Japan; Email: segino@urahp.yokohama-cu.ac.jp
}

\begin{abstract}
In a previous report, we showed that follicles isolated from frozen/thawed mouse ovarian tissues reached the mature follicle stage on the 12th day of culture. However, the developmental ability was lower than that of fresh ovarian tissue. The purpose of this study was to define a culture system with some technical modification for preantral follicles isolated from frozen/thawed ovarian tissue and to confirm cell injury. Ovaries obtained from three-week-old female mice were cryopreserved by the rapid freezing method. Preantral follicles isolated from frozen/thawed ovarian tissues were cultured for 12-16 days. The follicles were then stimulated with human chorionic gonadotropin. In vitro fertilization was performed on the released cumulus-oocyte complexes (COCs). Preantral follicle viability was assessed by supravital staining using Hoechst 33258 . Using this stain cell death was found in part of the granulosa cells of a follicle obtained from frozen/thawed ovarian tissue. On the 14th and 16th days of culture, the diameters of follicles isolated from frozen/thawed ovaries were larger than on the 12th day of culture. The released COCs were fertilized and developed to the blastocyst stage in $15.8 \%(12 / 76)$ of the oocytes taken from the fresh group, and in $0 \%(0 / 73), 2.9 \%(2 / 69)$ and $19.1 \%(22 / 115)$ of the oocytes taken from the frozen/thawed group that had been cultured for 12, 14 and 16 days respectively. The preantral follicles isolated from frozen/thawed mouse ovarian tissues developed slowly compared with the freshly prepared preantral follicles. During prolonged culture from 12 to 16 days, these follicles obtained the potential to fertilize and develop to the blastocyst stage.

Reproduction (2005) 130 187-192
\end{abstract}

\section{Introduction}

Cryopreservation of female gametes is an important technology for medical and scientific applications. There are two methods of obtaining mature oocytes from frozen/thawed ovarian tissues. One is transplantation and the other is isolation and culture of the follicles (or oocytes) obtained from ovarian tissues in vitro.

In 1953, Parkes and Smith reported success with the cryopreservation of ovarian tissues. Since then, normal offspring have been obtained from mice after orthotopic transplantation of cryopreserved ovarian tissues (Parrott 1960, Cox et al. 1996, Gunasena et al. 1997, Sztein et al. 1998). There is a risk that if cancer cells are present in the ovarian tissue at the time of cryopreservation, they may survive and will be transplanted. There are also ethical and moral problems with transplants of human ovarian tissue into immunodeficient animals (xeno-graft) for clinical applications. Thus in vitro growth of follicles (or oocytes) isolated from frozen/thawed ovarian tissues is desirable.
In the murine model, there are some reports that preantral follicles have been grown to the antral phase in vitro (Qvist et al. 1990, Nayudu \& Osborn 1992), were matured to metaphase II after human chorionic gonadotropin (hCG) stimulation (Cortvrindt \& Smitz 1998), were fertilized and developed into blastocysts (Cortvrindt et al. 1996a, Demeestere et al. 2002) and resulted in live births after embryo transfer (Spears et al. 1994). In 2001, Newton and Illingworth reported the survival and in vitro growth of murine follicles after isolation from ovarian tissues cryopreserved by a slow freezing method. They indicated that follicles isolated from frozen/thawed tissue produced mature oocytes, but at the end of the culture period the diameter of the frozen/thawed follicles was smaller than that of fresh ones.

In most previous studies, slow freezing methods using a programmed freezer have been employed for the cryopreservation of ovarian tissues (Parrott 1960, Cox et al. 1996, Gunasena et al. 1997, Sztein et al. 1998, Newton \& 
Illingworth 2001). Rall and Fahy (1985) reported an extremely rapid method called 'vitrification', in which embryos suspended in a high concentration of cryoprotectant solution were rapidly placed into liquid nitrogen. They used dimethylsulfoxide, acetamide and propylene glycol as the cryoprotectant. Ethylene glycol has been reported to be less toxic to embryos (Kasai et al. 1990, 1996, Mukaida et al. 1998) or oocytes (Rayos et al. 1994, Kuleshova et al. 1999) than other compounds. We have demonstrated that mature oocytes can be obtained after culture of follicles isolated from ovarian tissues frozen/thawed by a rapid freezing method (Segino et al. 2002, 2003). The size of the follicles obtained from the frozen/thawed ovarian tissues was smaller than those from freshly prepared controls after 12 days of culture. In addition, their developmental rates were lower compared with those of fresh follicles. In this paper we describe our studies of cell injury following cryopreservation and the time course of culture of preantral follicles obtained from frozen/thawed ovarian tissues.

\section{Materials and Methods}

\section{Animals and collection of ovarian tissue}

Three-week-old female $\mathrm{C} 57 \mathrm{BL} / 6 \mathrm{~N} \times \mathrm{DBA} / 2 \mathrm{~N}$ F1 mice (B6D2F1; CLEA Japan, Inc., Tokyo, Japan) were used in this study. They were housed under controlled conditions $(14 \mathrm{~h}$ light:10 h darkness) with food and water available ad libitum. The mice were killed by cervical dislocation and the ovaries were collected in Dulbecco's phosphate buffered saline (Sigma, St Louis, MO, USA) supplemented with $10 \%$ v/v fetal bovine serum (FBS; Sigma), $0.133 \mathrm{~g} / \mathrm{C} \mathrm{CaCl}_{2}-2 \mathrm{H}_{2} \mathrm{O}$, $0.1 \mathrm{~g} / \mathrm{l} \mathrm{MgCl}_{2}-6 \mathrm{H}_{2} \mathrm{O}, 1.0 \mathrm{~g} / \mathrm{l}$ D-glucose, $0.036 \mathrm{~g} / \mathrm{l}$ sodium pyruvate, $100 \mathrm{U} / \mathrm{ml}$ penicillin $\mathrm{G}, 0.1 \mathrm{~g} / \mathrm{l}$ streptomycin sulfate and $0.1 \mathrm{~g} / \mathrm{l}$ kanamycin sulfate (m-DPBS).

\section{Rapid freezing}

Five female mice were killed to obtain ovaries. These experiments were performed on four replications. The enveloping tissues were dissected from the collected ovaries and they were cut in half with a scalpel. They were cryopreserved by the modified rapid freezing method (Segino et al. 2002, 2003), which was based on a protocol for the rapid freezing of mouse embryos (Kasai et al. 1990). Briefly, they were treated in the following manner: EFS10 $(10 \% \mathrm{v} / \mathrm{v}$ ethylene glycol, $27 \% \mathrm{w} / \mathrm{v}$ Ficoll and $0.45 \mathrm{~mol} / \mathrm{l}$ sucrose) for $10 \mathrm{~min}$ at $25^{\circ} \mathrm{C}, \mathrm{EFS} 20(20 \% \mathrm{v} / \mathrm{v}$ ethylene gly$\mathrm{col}, 24 \% \mathrm{w} / \mathrm{v}$ Ficoll and $0.4 \mathrm{~mol} / \mathrm{l}$ sucrose) for $10 \mathrm{~min}$ at $4{ }^{\circ} \mathrm{C}$ and EFS40 (40\% v/v ethylene glycol, 18\% w/v Ficoll and $0.3 \mathrm{~mol} / \mathrm{l}$ sucrose) for $5 \mathrm{~min}$ at $4{ }^{\circ} \mathrm{C}$. Finally they were put into cryotubes with a small amount of cryoprotectant solution. Throughout all steps, ovarian pieces were continuously mixed with $1 \mathrm{ml}$ cryoprotectant solution on a shaker. The cryotubes were then exposed to the vapor phase above liquid nitrogen. After $3 \mathrm{~min}$, the cryotubes were plunged into liquid nitrogen and stored for 1-20 days. All cryoprotective solutions were prepared using m-DPBS.

\section{Thawing}

Following pulling up from liquid nitrogen, the ovarian tissues were placed in the air for $30 \mathrm{~s}$ at room temperature and then rinsed in EFS20 for $5 \mathrm{~min}$ at $4{ }^{\circ} \mathrm{C}$, EFS10 for $5 \mathrm{~min}$ at $25^{\circ} \mathrm{C}$ and $0.5 \mathrm{~mol} / \mathrm{l}$ sucrose for $10 \mathrm{~min}$ at $25^{\circ} \mathrm{C}$. Finally, they were put into $\mathrm{m}$-DPBS and washed 3 times. During all these steps they were continuously mixed using a shaker.

\section{Hoechst 33258 staining}

The viability of preantral follicles was assessed by supravital staining using Hoechst 33258 (bis-benzimide; Wako Pure Chemical Industries Co., Ltd, Osaka, Japan) as described in the literature (Jewgenow et al. 1998, Itoh \& Hoshi 2000). This staining has proved useful for the characterization of cell-membrane integrity by dye exclusion from viable cells. A preantral follicle obtained from frozen/thawed or fresh ovarian tissue was stained with $10 \mu \mathrm{g} / \mathrm{ml}$ Hoechst 33258 in culture medium for $15 \mathrm{~min}$ at $37^{\circ} \mathrm{C}$. Then, the follicle was evaluated under phase contrast microscopy with fluorescence excitation (Olympus, Tokyo, Japan).

\section{In vitro culture of preantral follicles}

Preantral follicles were obtained from the thawed ovaries by mechanical dissection with a 29-gauge insulin needle (Terumo, Leuven, Belgium) and transferred to fresh $\mathrm{m}$-DPBS. They were $100-130 \mu \mathrm{m}$ in diameter, spherical in structure, and consisted of two or three layers of granulosa cells and a visible oocyte. Selected follicles were washed three times before culture. A three-week-old female $\mathrm{C} 57 \mathrm{BL} / 6 \mathrm{~N} \times \mathrm{DBA} / 2 \mathrm{~N}$ F1 mouse was killed to obtain fresh ovaries as a control.

Mechanically isolated preantral follicles were individually cultured in alpha minimal essential medium ( $\alpha \mathrm{MEM}$; Life Technologies, Inc., Rockville, MD, USA), supplemented with $100 \mathrm{mU} / \mathrm{ml}$ human follicle stimulating hormone ( $\mathrm{hFSH}$, Fertinorm P; Serono, Geneva, Switzerland), $5 \mu \mathrm{g} / \mathrm{ml}$ insulin, $5 \mu \mathrm{g} / \mathrm{ml}$ transferrin, $5 \mathrm{ng} / \mathrm{ml}$ selenium (ITS; Sigma) and 5\% v/v FBS (Cortvrindt et al. 1996a). Twenty follicles were individually cultured in a culture dish $(60 \mathrm{~mm}$ tissue culture dish; Falcon, Becton Dickinson, Oxford, Oxon, UK), containing a $10 \mu \mathrm{l}$ droplet covered with $5 \mathrm{ml}$ mineral oil (Sigma), at $37^{\circ} \mathrm{C}$ in a humidified atmosphere of $5 \% \mathrm{CO}_{2}$ in air. On the second day of culture, $10 \mu \mathrm{l}$ medium were added to each droplet and thereafter half of the medium was exchanged every second day. On the 1st, 4th, 8th, 12th, 14th and 16th days of culture, oocyte and follicle diameter excluding the theca stroma was estimated by measuring two perpendicular diameters (length and width) with an ocular micrometer under the inverted microscope (Olympus). 


\section{Releasing of cumulus-oocyte complexes}

On the 12th, 14th or 16th day of culture, cumulus-oocyte complexes (COCs) were released from the antral follicles by the addition of $2.5 \mathrm{U} / \mathrm{ml}$ hCG (Gonatropin 3000; Teikoku Zoki, Co. Ltd, Tokyo, Japan) and $5 \mathrm{ng} / \mathrm{ml}$ epidermal growth factor (EGF; Sigma). Seventeen hours later, the released oocytes were classified as follows: GV when the germinal vesicle was present, germinal vesicle broken down (GVBD), or metaphase II (MII) when the first polar body was extruded.

\section{In vitro fertilization}

Preantral follicles obtained from 6 fresh ovarian tissues $(n=140)$ and 24 frozen/thawed ovarian tissues $(n=308)$ were cultured in 3 replications. Expanded COCs released from the antral follicles by the addition of hCG and EGF were placed in human tubal fluid medium (HTF; Irvine Scientific, Santa Ana, CA, USA) containing $0.4 \% \mathrm{w} / \mathrm{v}$ bovine serum albumin (BSA; Sigma). Caudal epididymal spermatozoa, collected from an adult B6D2F1 male, were used for insemination at concentrations of $1 \times 10^{6}$ sperm $/ \mathrm{ml}$. Oocytes were removed from the fertilization drops after $4-5 \mathrm{~h}$ and cultured in fresh medium for $120 \mathrm{~h}$.

\section{Hormonal assays}

On the 12th, 14th or 16th day of culture, conditioned media from individual follicles were collected for single follicles and stored at $-30^{\circ} \mathrm{C}$. Estradiol- $17 \beta$ in these media were measured by enzyme immunoassay (17 $\beta$ estradiol ELISA kit; IBL, Hamburg, Germany). This assay has been described in the literature (Cortvrindt et al. 1996a, Liu et al. 2002).

\section{Statistical analysis}

Category variables were assessed by calculating chisquare or Fisher's exact test in the case of small cell frequencies. Follicle diameter and hormonal levels were compared between the two groups using Student's $t$-test. All values are presented as means \pm S.E.

\section{Results}

\section{Viability of preantral follicles}

A viable preantral follicle obtained from a fresh ovary with granulosa cells and a germinal vesicle in the oocyte showed no staining with Hoechst 33258. In contrast, a little staining of the granulosa cells was found in a follicle obtained from frozen/thawed ovarian tissue but there was no staining of the oocyte (Fig. 1a,b).

\section{Growth of preantral follicles in vitro}

The number of preantral follicles isolated from individual fresh and frozen/thawed ovaries was $22.4 \pm 1.68$ and $13.4 \pm 0.73$ respectively (Fig. $2 a$ ). After 4 days of culture, the fresh ovarian follicles had increased in diameter while the size of the frozen/thawed ovarian follicles had not changed. After 12 days of culture, the diameter of follicles isolated from fresh and frozen/thawed ovaries were $620.6 \pm 12.67 \mu \mathrm{m}$ and $477.0 \pm 20.0 \mu \mathrm{m}$ respectively. Frozen/thawed ovarian follicles were cultured for a maximum of 16 days. On the 14th and 16th day of culture, the diameters were $560.3 \pm 20.5 \mu \mathrm{m}$ and $632.2 \pm 17.0 \mu \mathrm{m}$ respectively (Fig. 2b, Fig. 3).

The oocyte diameter of a selected follicle was measured in tissue taken from both the fresh (57.5 $\pm 0.46 \mu \mathrm{m}, n=88)$ and the frozen/thawed $(56.1 \pm 0.56 \mu \mathrm{m}, n=81)$ group. After 12 days of culture, the oocytes finally reached a diameter of $70.9 \pm 0.59 \mu \mathrm{m}$ and $70.2 \pm 0.46 \mu \mathrm{m}$ respectively. On the 14th and 16th day of culture, the diameters of the oocytes isolated from the frozen/thawed ovary were $72.7 \pm 0.51 \mu \mathrm{m}$ and $73.4 \pm 0.67 \mu \mathrm{m}$ respectively.

On the 12 th day of culture, $90.7 \%$ of the follicles in the fresh group survived. On the 12th, 14th and 16th day of culture, the survival rate of follicles isolated from frozen/thawed ovaries was $65.0 \%, 69.5 \%$ and $69.5 \%$ respectively (Table 1 ). During follicular growth, morphological degeneration was determined by extrusion of denuded oocytes and darkening of the ooplasm.

At the end of the culture period, the follicles were stimulated with hCG and EGF for $17 \mathrm{~h}$ to induce ovulation. COCs were expanded and were released from the follicle (Fig. 2c). The rate of released COCs from freshly isolated ovaries was $97.6 \%$. On the 12th, 14th and 16th day of culture, the rates of released COCs from

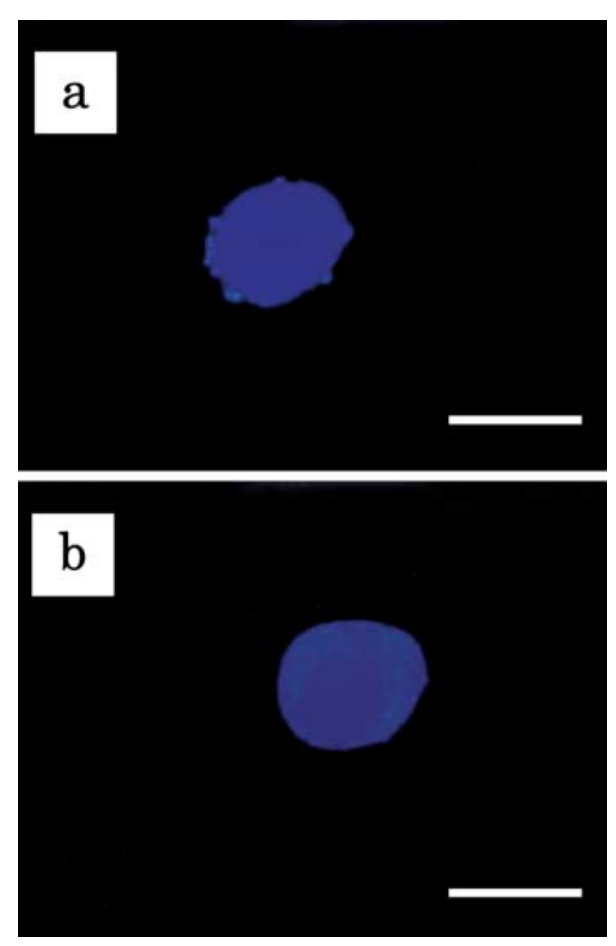

Figure $1 \mathrm{~A}$ preantral follicle isolated from (a) fresh and (b) frozen/thawed ovarian tissue stained with Hoechst 33258. Denatured cells were stained. Scale bar $=100 \mu \mathrm{m}$. 


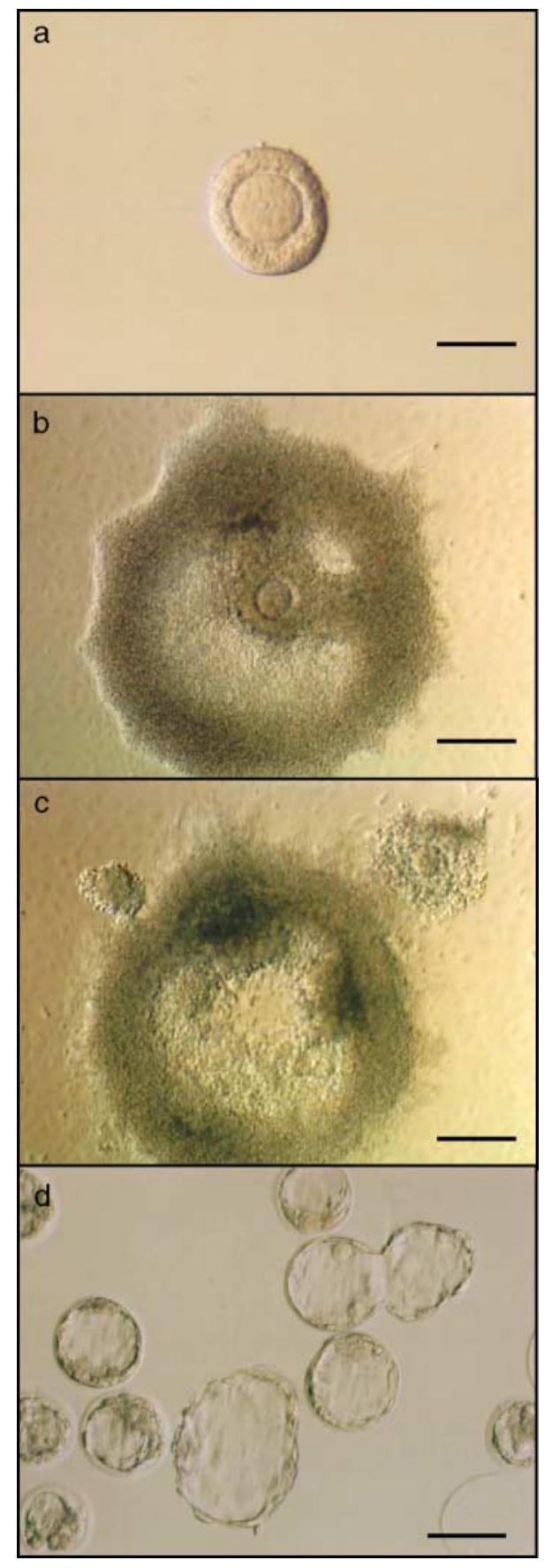

Figure 2 (a) A preantral follicle isolated from frozen/thawed ovarian tissue. (b) An antral follicle after 16 days of culture. (c) An antral follicle stimulated with hCG/EGF showing cumulus-oocyte complex extraction. (d) Blastocyst stage embryos in the frozen/thawed group. Scale bars: $\mathrm{a}=50 \mu \mathrm{m}, \mathrm{b}$ and $\mathrm{c}=200 \mu \mathrm{m}, \mathrm{d}=100 \mu \mathrm{m}$.

frozen/thawed ovaries were $84.3 \%, 91.2 \%$ and $93.8 \%$ respectively (Table 1 ).

\section{In vitro fertilization rate}

Expanded COCs were used for in vitro fertilization and preimplantation development. The fertilization rates were

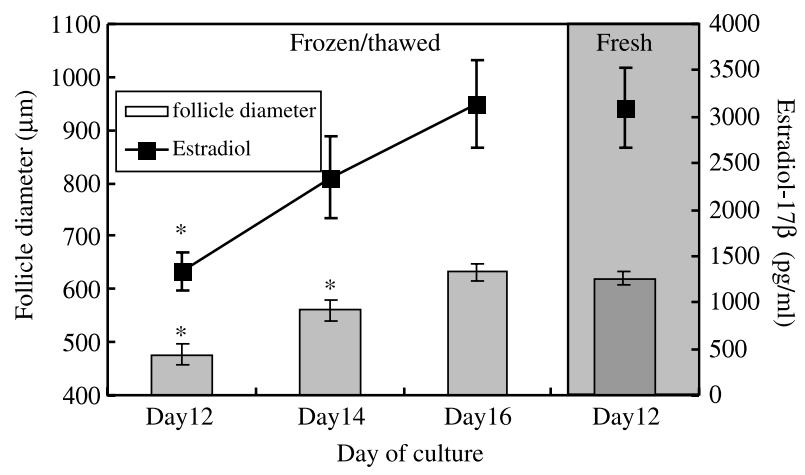

Figure 3 The diameter of preantral follicles and estradiol- $17 \beta$ concentrations in conditioned medium. The diameters of preantral follicles isolated from fresh $(n=88)$ and frozen/thawed $(n=81)$ ovarian tissues were measured. In the fresh group, estradiol- $17 \beta$ levels were measured by enzyme immunoassay on the 12th $(n=11)$ day of culture. In the frozen/thawed group, levels were measured on the 12th $(n=7), 14$ th $(n=7)$ and 16th $(n=7)$ day of culture. Values are means \pm S.E. $*(P<0.001)$. Significant differences are marked with fresh and frozen/thawed groups.

$73.7 \%$ in the fresh group, and $57.5 \%, 62.3 \%$ and $73.0 \%$ in the frozen/thawed group cultured for 12, 14 and 16 days respectively. Blastocysts were observed in $15.8 \%$ of the oocytes taken from the fresh group, and in $2.9 \%$ and $19.1 \%$ in the frozen/thawed group cultured for 14 and 16 days respectively (Table 2, Fig. 2 d).

\section{Hormonal assays}

The concentration of estradiol-17 $\beta$ in conditioned medium from fresh and frozen/thawed ovarian tissue is shown in Fig. 3. Estradiol-17 $\beta$ production by follicles isolated from fresh tissue was significantly greater than that produced by those isolated from frozen/thawed tissue $(3091.5 \pm 162 \mathrm{pg} / \mathrm{ml}$ vs $1339.6 \pm 203 \mathrm{pg} / \mathrm{ml})$. The production of estradiol-17 $\beta$ increased progressively up to 12 or 16 days. On the 14th and 16th day of culture, the estradiol-17 $\beta$ concentration of follicles isolated from frozen/thawed ovaries was $2346.1 \pm 435 \mathrm{pg} / \mathrm{ml}$ and $3138.5 \pm 472 \mathrm{pg} / \mathrm{ml}$ respectively. The estradiol $-17 \beta$ levels were not statistically different between 12 days of culture in the fresh group and 16 days of culture in the frozen/thawed group. Estradiol-17 $\beta$ is a lipid-soluble sterol that can easily diffuse into the surrounding oil. Liu et al. (2002) indicated that $<1 \%$ of the follicular secretory product was diffused to adjacent oil. Therefore, estradiol-17 $\beta$ concentrations in the collected media were used to monitor follicular estradiol- $17 \beta$ production in vitro.

\section{Discussion}

The survival rates of cryopreserved embryos depend upon several mechanisms related to cell injury, such as the chemical toxicity of the cryoprotectant, intracellular ice formation, fracture damage, and osmotic swelling during the removal of the cryoprotectant (Mukaida et al. 1998). 
Table 1 Acquisition of competent oocytes after in vitro maturation of preantral follicles. Preantral follicles isolated from fresh ovaries were cultured for 12 days. Preantral follicles isolated from frozen/thawed ovaries were cultured for 12, 14 or 16 days.

\begin{tabular}{|c|c|c|c|c|c|c|}
\hline \multirow[b]{2}{*}{ Follicles } & \multicolumn{3}{|c|}{ No. of follicles } & \multicolumn{3}{|c|}{ No. of oocytes } \\
\hline & Cultured & Survived & Released COCs & GV & GVBD & MII \\
\hline Fresh ovary & 140 & $127^{\mathrm{a}}(90.7 \%)$ & $124^{\mathrm{a}}(97.6 \%)$ & $9(7.3 \%)$ & $9^{a}(7.3 \%)$ & $106^{\mathrm{a}}(85.5 \%)$ \\
\hline \multicolumn{7}{|l|}{ Frozen/thawed ovary } \\
\hline Cultured for 12 days & 177 & $115^{\mathrm{c}}(65.0 \%)$ & $97^{\mathrm{C}}(84.3 \%)$ & $9(9.3 \%)$ & $27^{\mathrm{C}}(27.8 \%)$ & $61^{\mathrm{c}}(62.9 \%)$ \\
\hline Cultured for 14 days & 131 & $91^{\mathrm{c}}(69.5 \%)$ & $83^{b}(91.2 \%)$ & $7(8.4 \%)$ & $18^{\mathrm{b}}(21.7 \%)$ & $58^{\mathrm{b}}(69.9 \%)$ \\
\hline Cultured for 16 days & 210 & $146^{\mathrm{C}}(69.5 \%)$ & $137^{\mathrm{NS}}(93.8 \%)$ & $10(7.3 \%)$ & $22^{\mathrm{b}}(16.1 \%)$ & $105^{\mathrm{NS}}(76.6 \%)$ \\
\hline
\end{tabular}

Significant differences are compared with fresh group (a-b: $P<0.05$, a-c: $P<0.001$ ). NS, no significant differences. COCs, cumulusoocyte-complexes; GV, germinal vesicle; GVBD, germinal vesicle breakdown; MII, metaphase II.

The ovary is a complex structure composed of several different types of cells. By comparison with an oocyte or embryo, which is a single unit, cryopreservation of ovarian tissue is more difficult because different cell types have different requirements for optimal survival. We have shown that cell death was found in a part of the granulosa cells of a follicle obtained from frozen/thawed ovarian tissue. The lower survival rate of follicles isolated from frozen/thawed ovaries was ascribed to initial cell death of the granulosa cells.

Our culture system is based upon an established method by Cortvrindt et al. (1996a). They indicated that optimal maturity was obtained after 12-14 days, and that on the 16th day of culture there was a significantly lower maturity rate and a lower final yield of GVBD. In our experiment, the preantral follicles isolated from frozen/thawed ovarian tissue developed slowly compared with the freshly prepared preantral follicles. On the 12th day of culture, the diameters of follicles isolated from fresh ovaries were larger than those from frozen/thawed ovaries, and quantification of the estradiol- $17 \beta$ in the conditioned medium revealed lower production from the frozen/thawed follicles compared with the control follicles.

On the 16th day of culture, the diameter and estradiol$17 \beta$ production of follicles isolated from frozen/thawed ovaries reached the same level as those of fresh follicles on the 12th day. This might be a reflection of the number of intact granulosa cells present as a result of the initial cell death that occurred during the freeze/thaw process (Cortvrindt et al. 1996b, Newton \& Illingworth 2001).
In all experimental groups, MIl stage oocytes were observed in more than $60 \%$ of follicles after hCG/EGF stimulation. However, blastocysts were observed in the oocytes taken from the fresh group and the frozen/thawed group cultured for 14 and 16 days but not when cultured for 12 days. Oocyte maturity is often assessed only in terms of nuclear maturity, a visible parameter that can be easily observed under an inverted microscope. The processes of oocyte development involved in the acquisition of competence to undergo fertilization and preimplantation development are often referred to as cytoplasmic maturation. Eppig and Schroeder (1989) reported that oocytes matured and fertilized in vitro after isolation from small antral follicles are less likely to complete preimplantation development than oocytes from large antral follicles. Oocytes have to reach their full size and competence to undergo both nuclear and cytoplasmic maturation and thus support future completion of development.

In conclusion, we have demonstrated that cryopreservation of mouse ovarian tissues by rapid freezing is successful in allowing the oocytes to maintain their ability to undergo meiosis and preimplantation development. The freeze/thaw process may have some effects on growth suppression of the oocytes themselves and of granulosa cells. However, this impairment is within the range from which recovery is possible. Patients undergoing potentially sterilizing therapy for cancer need to protect their fertility before treatment. Recent studies demonstrate good rates of follicular survival and normal morphology after cryopreservation, but there are major uncertainties about the

Table 2 Fertilization rate and development of oocytes matured in vitro into the 2-cell, morula and blastocyst stages.

\begin{tabular}{|c|c|c|c|c|c|}
\hline \multirow[b]{2}{*}{ Follicles } & \multicolumn{2}{|c|}{ No. of oocytes } & \multicolumn{3}{|c|}{ No. of embryos } \\
\hline & Inseminated & Fertilized & 2-cell & Morula & Blastocyst \\
\hline Fresh ovary & 76 & $56^{\mathrm{a}}(73.7 \%)$ & $52^{\mathrm{a}}(68.4 \%)$ & $24^{\mathrm{a}}(31.6 \%)$ & $12^{\mathrm{a}}(15.8 \%)$ \\
\hline \multicolumn{6}{|l|}{ Frozen/thawed ovary } \\
\hline Cultured for 12 days & 73 & $42^{\mathrm{b}}(57.5 \%)$ & $31^{\mathrm{b}}(42.5 \%)$ & $7^{\mathrm{C}}(9.6 \%)$ & $0^{\mathrm{C}}$ \\
\hline Cultured for 14 days & 69 & $43^{\mathrm{NS}}(62.3 \%)$ & $43^{\mathrm{NS}}(62.3 \%)$ & $14^{\mathrm{NS}}(20.3 \%)$ & $2^{b}(2.9 \%)$ \\
\hline Cultured for 16 days & 115 & $84^{\mathrm{NS}}(73.0 \%)$ & $79^{N S}(68.7 \%)$ & $34^{\mathrm{NS}}(29.6 \%)$ & $22^{\mathrm{NS}}(19.1 \%)$ \\
\hline
\end{tabular}

Significant differences were compared with fresh group (a-b: $P<0.05$, a-c: $P<0.001)$. NS, no significant differences. 
best use of the tissue afterwards. Our study using mouse ovaries may provide the basis of clinical applications to human folliculogenesis for female gamete conservation.

\section{Acknowledgements}

We thank our colleagues and the present and past members of our laboratories who contributed to the research presented in this study. The authors declare that there is no conflict of interest that would prejudice the impartiality of this scientific work.

\section{References}

Cortvrindt R \& Smitz J 1998 Early preantral mouse follicle in vitro maturation: oocyte growth, meiotic maturation and granulosa-cell proliferation. Theriogenology 49 845-859.

Cortvrindt R, Smitz J \& Van Steirteghem AC 1996a In vitro maturation, fertilization and embryo development of immature oocytes from early preantral follicles from prepuberal mice in a simplified culture system. Human Reproduction 11 2656-2666.

Cortvrindt R, Smitz J \& Van Steirteghem AC 1996b A morphological and functional study of the effect of slow freezing followed by complete in vitro maturation of primary mouse ovarian follicles. Human Reproduction 11 2648-2655.

Cox SL, Shaw J \& Jenkin G 1996 Transplantation of cryopreserved fetal ovarian tissue to adult recipients in mice. Journal of Reproduction and Fertility 107 315-322.

Demeestere I, Delbaere A, Gervy C, Van Den Bergh M, Devreker F \& Englert Y 2002 Effect of preantral follicle isolation technique on in vitro follicular growth, oocyte maturation and embryo development in mice. Human Reproduction 17 2152-2159.

Eppig JJ \& Schroeder AC 1989 Capacity of mouse oocytes from preantral follicles to undergo embryogenesis and development to live young after growth, maturation, and fertilization in vitro. Biology of Reproduction 41 268-276.

Gunasena KT, Villines PM, Critser ES \& Critser JK 1997 Live births after autologous transplant of cryopreserved mouse ovaries. Human Reproduction 12 101-106.

Itoh T \& Hoshi H 2000 Efficient isolation and long-term viability of bovine small preantral follicles in vitro. In Vitro Cellular and Developmental Biology - Animal 36 235-240.

Jewgenow K, Penfold LM, Meyer HH \& Wildt DE 1998 Viability of small preantral ovarian follicles from domestic cats after cryoprotectant exposure and cryopreservation. Journal of Reproduction and Fertility 112 39-47.

Kasai M, Komi JH, Takakamo A, Tsudera H, Sakurai T \& Machida T 1990 A simple method for mouse embryo cryopreservation in a low toxicity vitrification solution, without appreciable loss of viability. Journal of Reproduction and Fertility 89 91-97.

Kasai M, Zhu SE, Pedro PB, Nakamura K, Sakurai T \& Edashige K 1996 Fracture damage of embryos and its prevention during vitrification and warming. Cryobiology 33 459-464.
Kuleshova LL, MacFarlane DR, Trounson AO \& Shaw JM 1999 Sugars exert a major influence on the vitrification properties of ethylene glycol-based solutions and have low toxicity to embryos and oocytes. Cryobiology 38 119-130.

Liu HC, He Z \& Rosenwaks Z 2002 In vitro culture and in vitro maturation of mouse preantral follicles with recombinant gonadotropins. Fertility and Sterility 77 373-383.

Mukaida T, Wada S, Takahashi K, Pedro PB, An TZ \& Kasai M 1998 Vitrification of human embryos based on the assessment of suitable conditions for 8-cell mouse embryos. Human Reproduction $132874-2879$.

Nayudu PL \& Osborn SM 1992 Factors influencing the rate of preantral and antral growth of mouse ovarian follicles in vitro. Journal of Reproduction and Fertility 95 349-362.

Newton H \& Illingworth P 2001 In vitro growth of murine pre-antral follicles after isolation from cryopreserved ovarian tissue. Human Reproduction 16 423-429.

Parkes AS \& Smith AU 1953 Regeneration of rat ovarian tissue grafted after exposure to low temperatures. Proceedings of the Royal Society B $140455-470$.

Parrott DM 1960 The fertility of mice with orthotopic ovarian grafts derived from frozen tissue. Journal of Reproduction and Fertility $\mathbf{1}$ 230-241.

Qvist R, Blackwell LF, Bourne H \& Brown JB 1990 Development of mouse ovarian follicles from primary to preovulatory stages in vitro. Journal of Reproduction and Fertility 89 169-180.

Rall WF \& Fahy GM 1985 Ice-free cryopreservation of mouse embryos at -196 degrees $C$ by vitrification. Nature 313 573-575.

Rayos AA, Takahashi Y, Hishinuma M \& Kanagawa H 1994 Quick freezing of unfertilized mouse oocytes using ethylene glycol with sucrose or trehalose. Journal of Reproduction and Fertility $\mathbf{1 0 0}$ 123-129.

Segino $M$, Ikeda $M$, Ishikawa $M$, Sakakibara $H$, Murase $M$, Ishiyama T, Torii M, Hirahara F \& Sato K 2002 Cryopreservation of mouse germinal vesicle oocytes and ovarian tissues by vitrification. Japan Society of Fertilization and Implantation 19 131-133.

Segino M, Ikeda M, Aoki S, Tokieda Y, Hirahara F \& Sato K 2003 In vitro culture of mouse GV oocytes and preantral follicles isolated from ovarian tissues cryopreserved by vitrification. Human Cell 16 109-116.

Spears N, Boland NI, Murray AA \& Gosden RG 1994 Mouse oocytes derived from in vitro grown primary ovarian follicles are fertile. Human Reproduction 9 527-532.

Sugimoto M, Maeda S, Manabe N \& Miyamoto H 1999 Development of infantile rat ovaries autotransplanted after cryopreservation by vitrification. Theriogenology 53 1093-1103.

Sztein J, Sweet H, Farley J \& Mobraaten L 1998 Cryopreservation and orthotopic transplantation of mouse ovaries: new approach in gamete banking. Biology of Reproduction 58 1071-1074.

Received 7 October 2004

First decision 23 December 2004

Revised manuscript received 20 April 2005

Accepted 18 May 2005 